\title{
England football fixtures lead to more OMFS admissions
}

\section{Oral and maxillofacial surgery (OMFS)} units should plan for increased admissions the day after major football fixtures, according to the OMFS team at Sunderland Royal Hospital in a new paper that found an increase of $58 \%{ }^{1}$

Lead author OMFS Rob Banks said that it is 'common for staff in OMFS departments to mutter "we're in for a busy day" after seeing a link between the 2018 Football World Cup and OMFS-related presentations to Sunderland Royal Hospital's ED'.

The authors analysed the patients who were admitted to OMFS via the hospital's ED on the same day as the football match and the following day.

Rob Banks said they found the mean number of patients attending the Sunderland Royal ED and admitted to OMFS increased the day after an England match from 2.53 to 4.00 - an increase of 58\%: 'We didn't find evidence that admissions rose on match day, but patients came to ED for help after the fixture, which had also increased the severity of acute symptoms.

'We concluded from the

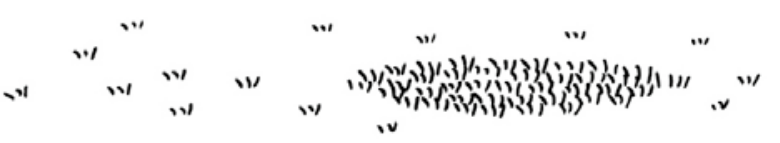

Sunderland Royal experience that OMFS units across the UK should expect the number of patients to increase the day after a

the latest (football) match being streamed nationwide'. As a result, he and his colleagues decided to investigate whether this was 言 actually happening.

'To our knowledge, few recent studies have assessed the impact large-scale sporting 产 events have on a hospital specialty in the UK,' ๑ै said Rob Banks. 'So, we decided to establish national sporting fixture.'

\section{Reference}

1. Miller N, Kearns A, Bartram A, Banks R. The real penalty: number of OMFS patients presenting to the emergency department at Sunderland Royal Hospital after England fixtures before and during the 2018 FIFA Football World Cup. Br J Oral Maxillofac Surg 2019; doi: 10.1016/j.bjoms.2019.10.313 [Epub ahead of print].

\section{BOS mourns orthodontist Chris Kettler MBE}

Members of the British Orthodontic Society (BOS) and affiliated groups are deeply saddened by the death of orthodontist Chris Kettler MBE, a towering figure in the world of orthodontics. He made an invaluable contribution to the formation of BOS in 1994, becoming the first Secretary of the BOS, and was still working for the Society this year as a member of the Archive and Museum Committee.

David Tidy followed Chris as

Secretary of BOS and recalls that both of them preferred to work behind the scenes. Chris in fact declined the role of President. David said: 'Chris was an influential and tireless figure in his work with the BOS but he never wanted to be the figurehead. At the same time through his practice he pioneered changes in the contracts for NHS orthodontics and he was a prominent advocate of orthodontic therapists. Latterly in the BOS Archive and Museum Committee he was a great asset because he knew so much of the history.' 